\title{
Development and Mechanical Characterization of a Non-Isocyanate Rigid Polyurethane Foam
}

\author{
Kostopoulos $\mathbf{V}^{1,2 *}$ and Kollia $\mathbf{E}^{1}$ \\ ${ }^{1}$ Department of Mechanical Engineering and Aeronautics, Greece \\ ${ }^{2}$ Institute of Chemical Engineering Sciences, Foundation for Research and Technology, Greece
}

ISSN: 2576-8840

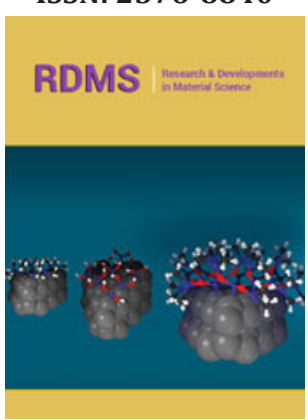

*Corresponding author: Kostopoulos V, Applied Mechanics and Vibrations Laboratory, Department of Mechanical Engineering and Aeronautics, University of Patras, Patras University Campus, GR26500 Patras, Greece

Submission: 悳 March 27, 2019

Published: 潠 April 01, 2019

Volume 10 - Issue 3

How to cite this article: Kostopoulos V, Kollia E. Development and Mechanical Characterization of a Non-Isocyanate Rigid Polyurethane Foam. Res Dev Material Sci. 10(3).RDMS.000738.2019.

DOI: 10.31031/RDMS.2019.10.000738

Copyright@ Kostopoulos V, This article is distributed under the terms of the Creative Commons Attribution 4.0 International License, which permits unrestricted use and redistribution provided that the original author and source are credited.

\begin{abstract}
The present work is a first attempt for the development of non-isocyanate polyurethane rigid foam. Two-component hybrid non-isocyanate polyurethane compound was used as the baseline. Different types of chemical products were used as blowing agents, among them Petroleum ether and high purity Cyclopentane. Moreover, the addition of organic nanoparticles at different loading content $(2,3$ and $5 \% \mathrm{wt}$ ) was tested to promote the foaming process, reduce the foam density, homogenize the size of foam cells, and increase mechanical properties of the final rigid foams. The main achievement of the present study is that non-isocyanate rigid foams with reasonable good mechanical characteristics can be developed using non-isocyanate compounds. Furthermore, the addition of nanoparticles during the foaming process, provides a mean to control density, and concludes to increased mechanical properties.
\end{abstract}

Keywords: Non-isocyanate; Rigid polyurethane foams; Nanoclays; Mechanical properties

\section{Introduction}

Polyurethanes (PU) are versatile polymers, which have traditionally been manufactured from petroleum-based ingredients [1]. The range of polyurethane products includes polyurethane resins, elastomers [2], sheets [2], adhesives [3], coatings [4], and foams [2], spanning their uses across a large array of industries and products. Factors such as the price and availability of petroleum, and societal concerns over global climate change continue to create increased market pressure on the industrial and domestic use of petrochemicals. The polyurethane industry has recently tended toward the replacement of petrochemical materials with renewable resources. With the improvement of our environmental protection consciousness, Diphenyl Methanediisocyanate (MDI) is an important organic isocyanate, with the advantages of low volatility and small toxicity. Therefore, MDI was welcomed by the polyurethane industry. Polyurethane foams can be flexible, semi-rigid or rigid by changing the types or amounts of polyols, polyisocyanates, blowing agents, catalyst and surfactant to suit their end needs [5]. Meng et al. [6] were produced an environmentally friendly MDI-based water-blown flexible polyurethane foam by using modified MDI and highly active polyether polyols as the main raw material, and water as blowing agent by the one-shot method. They observed that as the water content was increased the rise time, the gel time and the density were decreased. Additionally, they noticed that with the increase of water content from $2.5 \%$ to $4 \%$ the tensile strength of the MDI-based polyurethane flexible foam was also increased. Renewable resources such as vegetable oil is fast replacing the conventional fossil fuel derived oligomers in polyurethane synthesis [7-9]. Castor oil is a major candidate in these replacement efforts, due to its inherent advantages over other vegetable oils. The major content of the triglyceride fatty acid residue of castor oil is ricinoleic acid. Ricinoleic acid has inherent hydroxyl groups in their parent hydrocarbon chain due to which the need to introduce hydroxyl groups can be avoided or at least minimize [8]. Some early reports indicate the use of castor oil in making thermally insulating rigid polyurethane foams $[10,11]$. Castor oil modified with maleic anhydride was used to synthesize biodegradable foams [12]. Diethanol amides of castor oil are reported to be used for water blown polyurethane foams [13]. Castor-oil substituted partially in the synthesis of flexible polyurethane foam resulted in an increase of density and hardness index, but a decrease in tensile strength and elongation [14]. Cinelli et al. [15] produced soft foams from Kraft lignin using two types of 
chain extenders, polypropilenglycol triol and castor oil and water as blowing agent. They concluded that the parameters that affect the mechanical properties of foams are the thickness and length of cell strut. It has been reported that the degradation of urethane bond of Rigid Polyurethane Foams (RPUF) starts at 200-250 ${ }^{\circ} \mathrm{C}$ [16-18].

A great effort has been devoted to the development of nanostructured polyurethane (PU)/montmorillonite (MMT) composites in recent years [19-22]. The effects of clay type, clay content, and PU molecular structure on clay dispersion in thermoplastic PU nanocomposites have been studied. It has been found that MMT clays have good compatibility with polyol and improves the tensile properties of the matrix as well as the strainat-break. Nanoscale-dispersed clay may act as nucleation agents during the foaming process to produce finer cell structure and higher cell density. Furthermore, improved gas barrier properties [20] provide another opportunity for application of nanoclay in PU foams.

Growing concerns about toxicity, control of $\mathrm{CO}_{2}$ emissions, biodegradability and other environmental problems are driving the research for alternative blowing agents. A considerable body of work has been already published related to the use of organic isocyanate such as Diphenyl Methanediisocyanate (MDI) but to the authors' knowledge, the literature regarding the nonisocyanate polyurethane foams (NIPUR) is very limited. Furthermore, the literature regarding the use of nanoclays in the reactive PU foaming process is also very limited. The present study contributes to this field by developing a rigid NIPUR using a conventional nonisocyanate PU bulk material and compares its mechanical properties and density with nano-doped rigid NIPUR foams.

\section{Experimental}

\section{Materials}

A two-component hybrid non-isocyanate polyurethane compound was used as the baseline, provided by Polymate, Israel with the commercial grade designation ECPU 4761ULS. The mixing ratio, part A: part B, used was $100: 39$ by weight. Different types of chemical products were used as blowing agents, among them Petroleum ether and high purity Cyclopentane, provided by Technobiochem, Greece. Organic nanoparticles, Cloisite 30B (methyl tallow bis-2-hydroxyethyl) quaternary ammonium modified montmorillonite $(\mathrm{d} 001=18.5 \AA)$ with a concentration of $90 \mathrm{meq} / 100 \mathrm{~g}$ clay (cation exchange capacity in milliequivalents per 100 gram) provided by Rockwood Additives UK, used for modifying the PU foam.

\section{Development of rigid PU foam with nanoclays}

During the first trials, reference rigid NIPUR foams were produced using two different types of blowing agents, namely: high purity Cyclopentane and Petroleum ether. Since, based on the first trials, the foams produced by using cyclopentane as blowing agent conclude to lower density compared to ones produced by using Petroleum ether (Table 1), the study was focused on the first blowing approach. In the case of nanomodified rigid NIPUR foams, nanoclays were used. Nanoclays, i.e. Cloisite 30B nanoparticles with an average size of $6 \mu \mathrm{m}$, were dehydrated under vacuum at 70 ${ }^{\circ} \mathrm{C}$ overnight before used. RPUFs were developed by first mixing the nanoclays with the part A of the PU material. 3 roll-mill was used to achieve the homogeneous dispersion of the nanoparticles in the final part A mixture. In the present study the distance between the rollers of the 3 roll-mill variates from $120 \mu \mathrm{m}$ to $5 \mu \mathrm{m}$ depending on the milling cycle. The sequential gap settings were 120, 40, 10 and 6 $\mu \mathrm{m}$ respectively, and three cycles of milling were repeated for each gap setting. The speed of the roll was maintained at $270 \mathrm{rpm}$. After the application of the mixing process, part B was added in the blend and stirred well until uniform mixture was obtained. Cyclopentane was then used as blowing agent at $5.5 \mathrm{wt} \%$ and stirred at once and placed in an oven at $60^{\circ} \mathrm{C}$ until it began to foam. The last step of the development was to keep the foams into the oven at $60^{\circ} \mathrm{C}$ for $8 \mathrm{~h}$ to ensure completion of the reaction/polymerization process.

The schematic representation of the foaming process is given in Figure 1, where also the step by step development of the nanodoped rigid NIPUR foam is presented schematically.

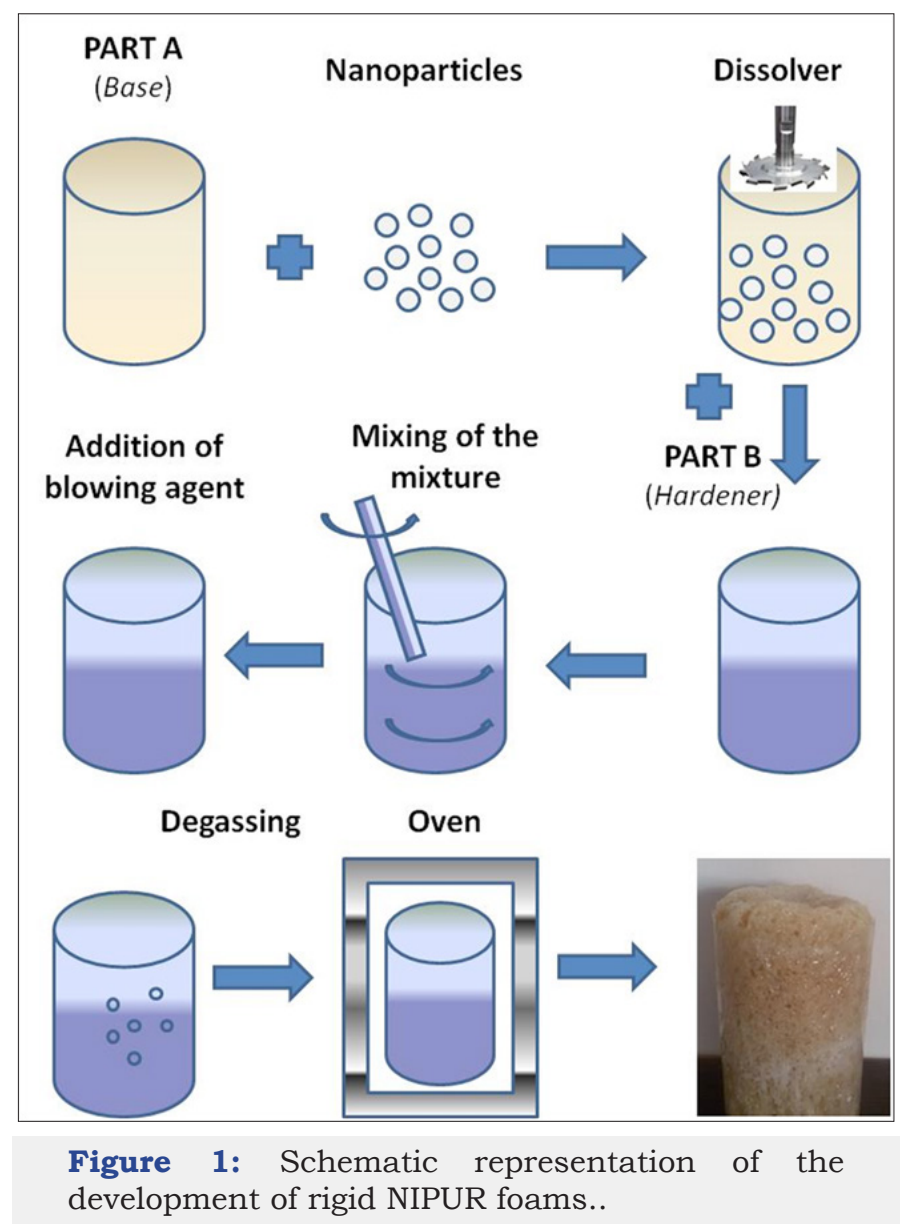

There are three different groups of produced and examined rigid non-isocyanate PU foams as indicted below (Figure 2):

1. Reference PU foam, where Petroleum ether was used as blowing agent

2. Reference PU foam, where cyclopentane was used as blowing agent 
3. PU foam, where cyclopentane used as blowing agent and different \%wt loadings of nanoclays were used.
Figure 3 depicts some samples of the developed rigid NIPUR foams before the implementation of compression test.

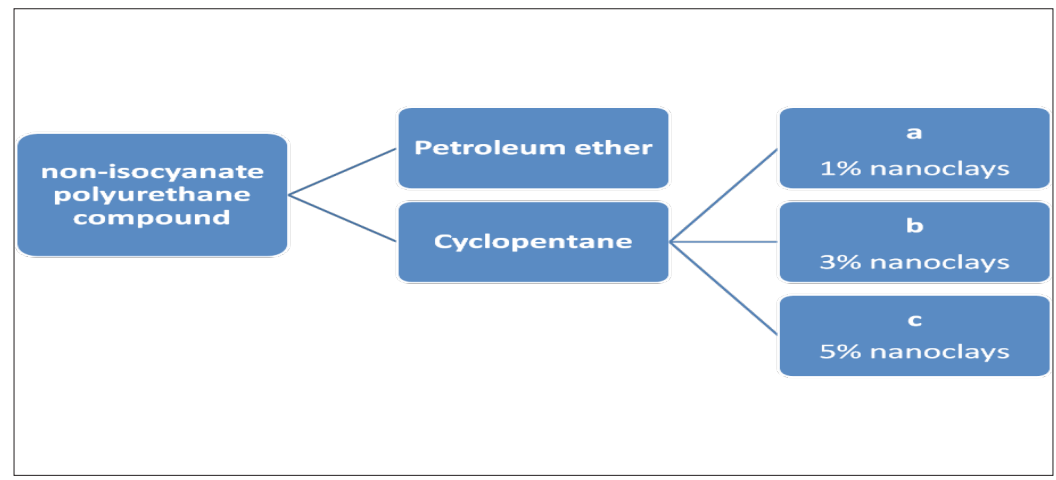

Figure 2: The three different groups of rigid NIPU foams.

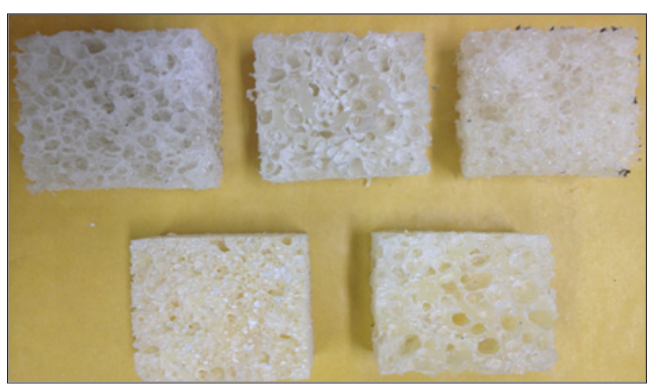

Figure 3: Samples of rigid NIPUR foams.

\section{Measurements and characterization}

The density of rigid foams was calculated based on ASTM D 1622-03.

The compressive strength and modulus parallel to the rising/ foaming direction of foam samples, were measured by using an INSTRON servo-hydraulic testing machine according to ASTM D1621. The test specimens had dimensions of $25.4 \times 25.4 \times 12.7 \mathrm{~mm}^{3}$ and the crosshead velocity in compression was set at $1.2 \mathrm{~mm} / \mathrm{min}$. The compression tests were stopped at compression strain of $10 \%$.

\section{Scanning Electron Microscopy (SEM)}

Scanning Electron Microscopy was carried out to investigate the surface morphology of the rigid NIPU foams. Images were taken using the EVO MA 10 Zeiss SEM microscope. The surface of samples was prepared using sputter coating with a thin conducting layer of gold.

\section{Optical Microscopy (OM)}

Optical Microscopy observations were carried out in a ZEISS Axio Observer 7 materials apparatus for the characterization of the cell size distribution, for the reference and nano-modified NIPUR foams.

\section{Results and discussion}

The properties of the nanoclay reinforced foams are mainly dependent on the nanoclay concentration and the dispersion process/quality followed. The effect of the blowing agent and

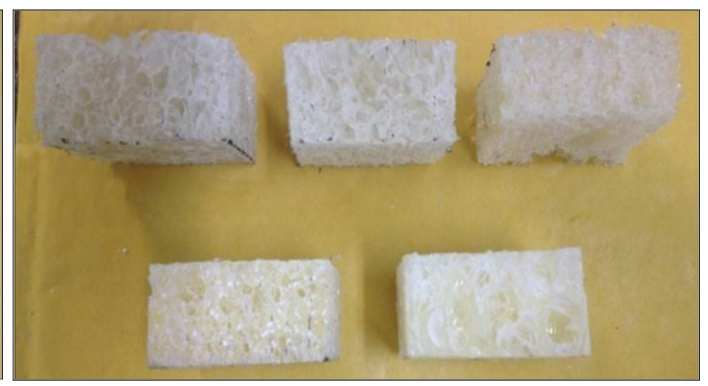

the nanoclays concentration on the density and the mechanical properties of the NIPU foams are depicted in Table 1.

From Table 1 it is obvious that the blowing agent affects the final density of the foam, and as a direct result its properties. The density of PU foams is a key parameter and good indicator of its performance. The foam produced by using cyclopentane as blowing agent, exhibits a lower density compared to the foam produced using petroleum ether.

The resulted foams using petroleum ether as blowing agent was the heaviest ones, and this figure was not changed by differentiating the way of the mixing process and the activation temperature. Furthermore, the cell size was varied significantly from some micrometers to several millimeters, whereas the wall thickness of the cells was not constant. This means that the foaming process was not controlled.

In the case of high purity cyclopentane that was used as foaming agent for the reference NIPU material, the foaming process was smoother, and the final product presents lower density compare to the petroleum ether activated foams, of about $25 \%$, while the cell size was more uniform in this case. Based on the above-mentioned results, it was intended to further reduce the foam density, but this was not achieved by changing the foaming process and temperature. Thus, the addition of organic nano-particles was decided in order to increase the nucleation points during the foaming process, thus concluded to lower density foams and thinner cell size.

The addition of nanoclays in the NIPUR foams was applied only in the case of the foams where cyclopentane used as blowing agent. 
Three different \% wt nanoclays content (namely 2\%, 3\% and 5\%) was used in the NIPUR and it was shown that the density of the resulted foam reduces increasing the $\%$ wt of the nanoclays content.

Table 1: Optical Microscopy observation and bar graph with number of cells as a function of the diameter of cells in mm.

\begin{tabular}{|c|c|c|c|}
\hline $\begin{array}{c}\text { Foaming Agent } \\
\& \\
\text { (\% wt Nanoclays) }\end{array}$ & $\begin{array}{c}\text { Optical Microscopy } \\
\text { (Observation/Image Analysis) }\end{array}$ & & $\begin{array}{l}\text { Bar Graph Derived from om Image Analysis } \\
\text { (\%Percentage of Cells vs Diameter of Cells) }\end{array}$ \\
\hline $\begin{array}{l}\text { Petroleum ether } \\
\text { (0\% wt nanoclays) }\end{array}$ & 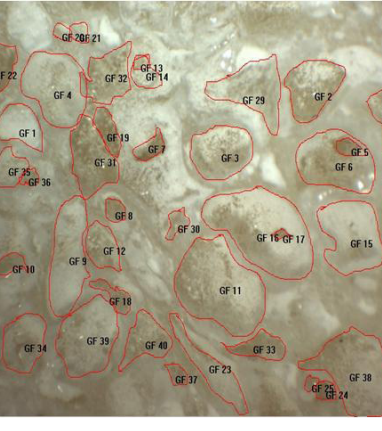 & 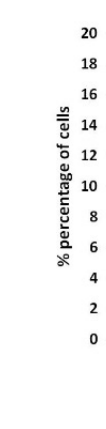 & $\begin{array}{c}\text { Petroleum ether } \\
\\
\\
\\
0\end{array}$ \\
\hline $\begin{array}{l}\text { Cyclopentane } \\
\text { (0\% wt nanoclays) }\end{array}$ & ${ }_{6 F 32}^{6 F 33}$ & 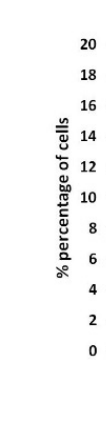 & 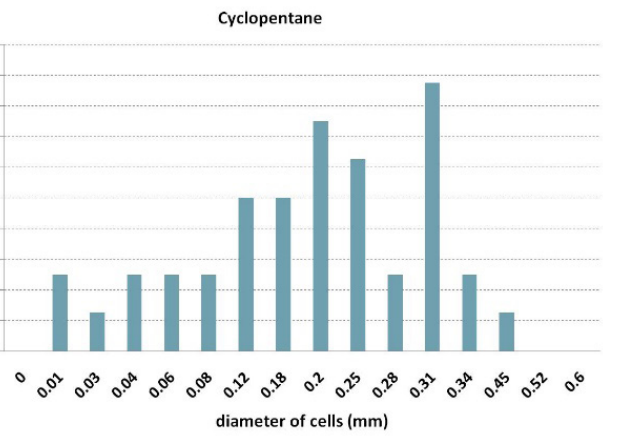 \\
\hline $\begin{array}{l}\text { Cyclopentane } \\
\text { (2\% wt nanoclays) }\end{array}$ & GF23 & 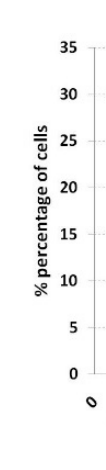 & 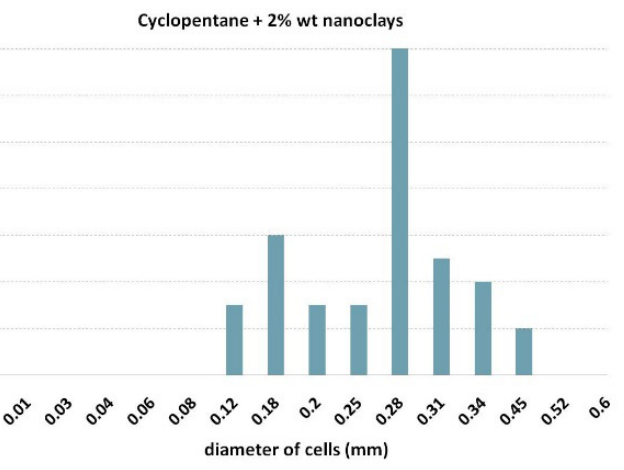 \\
\hline $\begin{array}{l}\text { Cyclopentane } \\
\text { (3\% wt nanoclays) }\end{array}$ & GF 31 GF & 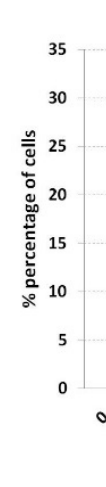 & 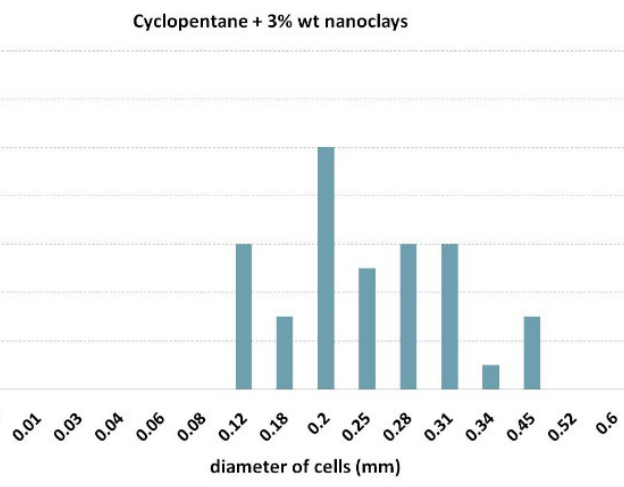 \\
\hline
\end{tabular}



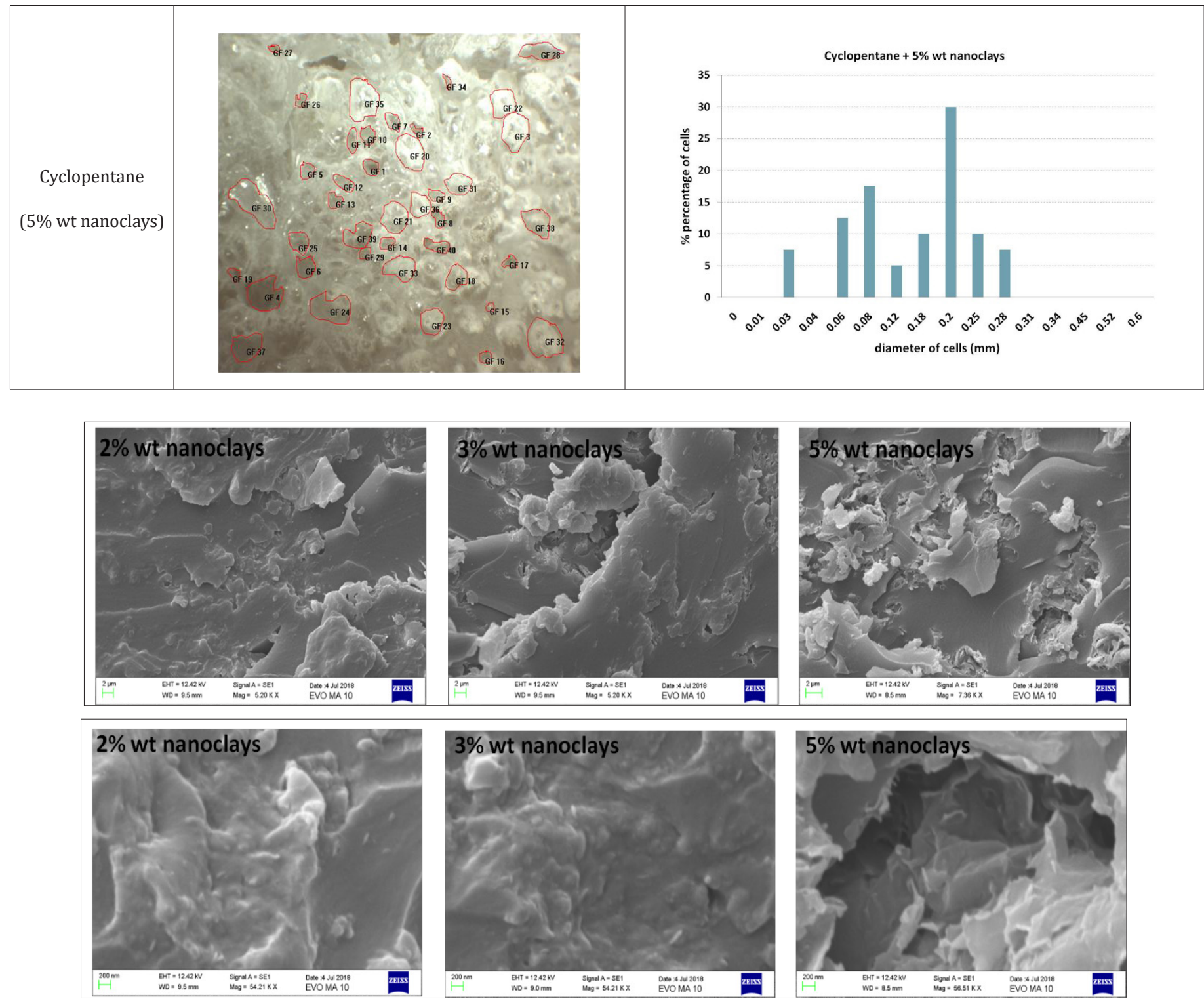

Figure 4: SEM images of rigid NIPU foams reinforced with $2 \%, 3 \%$ and $5 \%$ wt. nanoclays.

Figure 4 presents SEM photos of NIPUR for the different \% wt nanoclays content. As it is shown in the case of $2 \%$ and $3 \%$ wt nanoclays content a uniform dispersion has been achieved, and the nanoclays are incorporated in the wall cells of the foam. In contrast, in the case of 5\%wt. nanoclays content, as shown in Figure 5 , various regions with nanoclays clusters (agglomerates) can be identified, which appears in the form of defects in the wall of the cells.

Table 1 presents optical microscope images of typical cross sections of PU rigid foams received normal to the foam direction. Using several representative cross sections, the diameter of the cells was investigated. Image analysis software was used to measure the size and the equivalent diameter of the cells in all types of foam samples. The main purpose of the cell size measurements was to behold how foaming agent and the addition of nanoclays affects the foaming process and consequently the size of the foam cells. Toward this direction, the third column of Table 1, include the bar charts, which show the \% percentage of foam cells as a function of their diameter. A careful analysis of the bar chards shows that the use of cyclopentane as foaming agent results to more homogeneous and slightly lower cell diameter. Furthermore, the addition of nanoclays can effectively reduce the cell diameter and form more uniform cell structure compared against the case on reference $(0 \%$ wt nanoclays) foam. This conclusion derived from the variation of the values of the equivalent diameter of cells. This result agrees with the literature and shows that nanoclays can act as nucleating agent by introducing bubble growing points and form more cells with smaller size [23].

The compressive strength and the corresponding modulus were measured to study the effect of blowing agents and the addition of nanoclays on the mechanical properties of NIPUR foams. Five samples from each material batch were tested and the results are summarized in Table 2. In the case of unreinforced foams, the ones produced using petroleum ether and have, as mentioned earlier, the higher density and concludes to higher modulus and higher strength. Typical stress-strain curves are given in Figure 5. It is 
interesting to notice that although petroleum ether foamed NIPUR has 30\% higher density, it has 3 times the modulus and almost double strength compared against the NIPUR, where cyclopentane was used as foaming agent. However, all efforts made to reduce the density of petroleum ether foamed NIPUR were failed and for this reason all trials for producing lighter foams were concentrated to the use of cyclopentane as foaming agent.

Table 2: Properties of rigid NIPU foams.

\begin{tabular}{|c|c|c|c|c|c|c|c|c|}
\hline \multirow{2}{*}{$\begin{array}{c}\text { Foaming Agent } \\
\& \\
\text { (\% wt Nanoclays) }\end{array}$} & \multicolumn{2}{|c|}{ Density $\left(\mathrm{Kg} / \mathrm{m}^{3}\right)$} & \multicolumn{2}{|c|}{$\begin{array}{c}\text { Compressive Strength } \\
\text { (GPa) }\end{array}$} & \multicolumn{2}{|c|}{$\begin{array}{c}\text { Compressive Modulus } \\
\text { (MPa) }\end{array}$} & \multicolumn{2}{|c|}{$\begin{array}{c}\text { Absorbed Energy at } \\
10 \%(\mathrm{~J})\end{array}$} \\
\hline & $\begin{array}{l}\text { Mean } \\
\text { value }\end{array}$ & SSD & Mean value & SSD & $\begin{array}{l}\text { Mean } \\
\text { value }\end{array}$ & SSD & $\begin{array}{l}\text { Mean } \\
\text { value }\end{array}$ & SSD \\
\hline Petroleum ether ( $0 \%$ wt nanoclays) & 398 & 15 & 8.2 & 0.4 & 157 & 10 & 4.5 & 0.05 \\
\hline Cyclopentane (0\% wt nanoclays) & 296 & 12 & 4.7 & 0.3 & 43 & 4.2 & 3.6 & 0.1 \\
\hline Cyclopentane (2\% wt nanoclays) & 197 & 10 & 0.65 & 0.2 & 10 & 0.8 & 0.65 & 0.05 \\
\hline Cyclopentane (3\% wt nanoclays) & 178 & 10 & 0.9 & 0.02 & 19 & 0.5 & 1.1 & 0.02 \\
\hline Cyclopentane (5\% wt nanoclays) & 103 & 6 & 0.2 & 0.01 & 3 & 0.1 & 0.5 & 0.02 \\
\hline
\end{tabular}

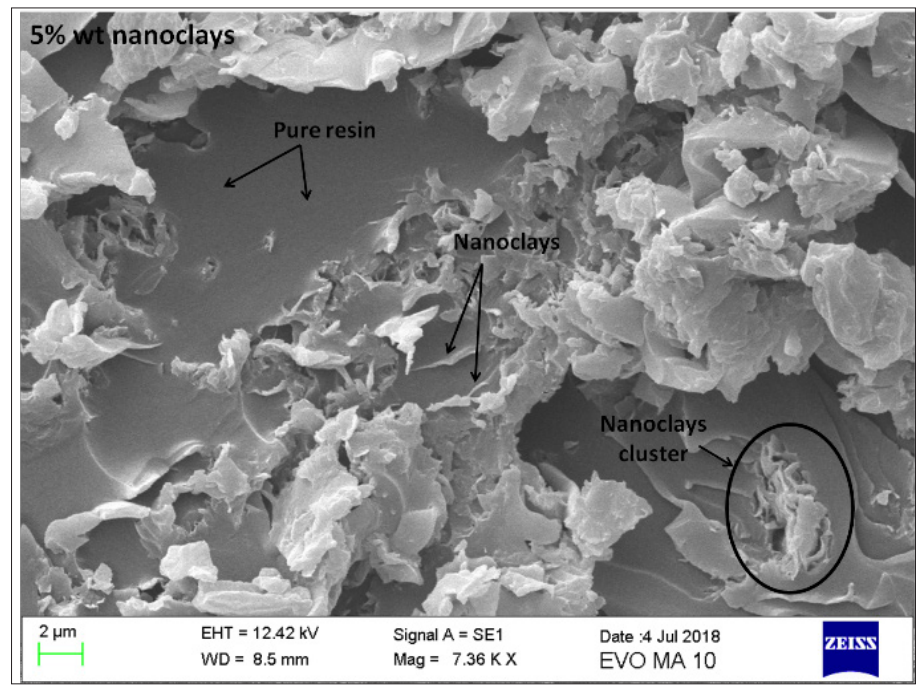

Figure 5: SEM images of rigid NIPU foams reinforced with 5\% wt nanoclays.

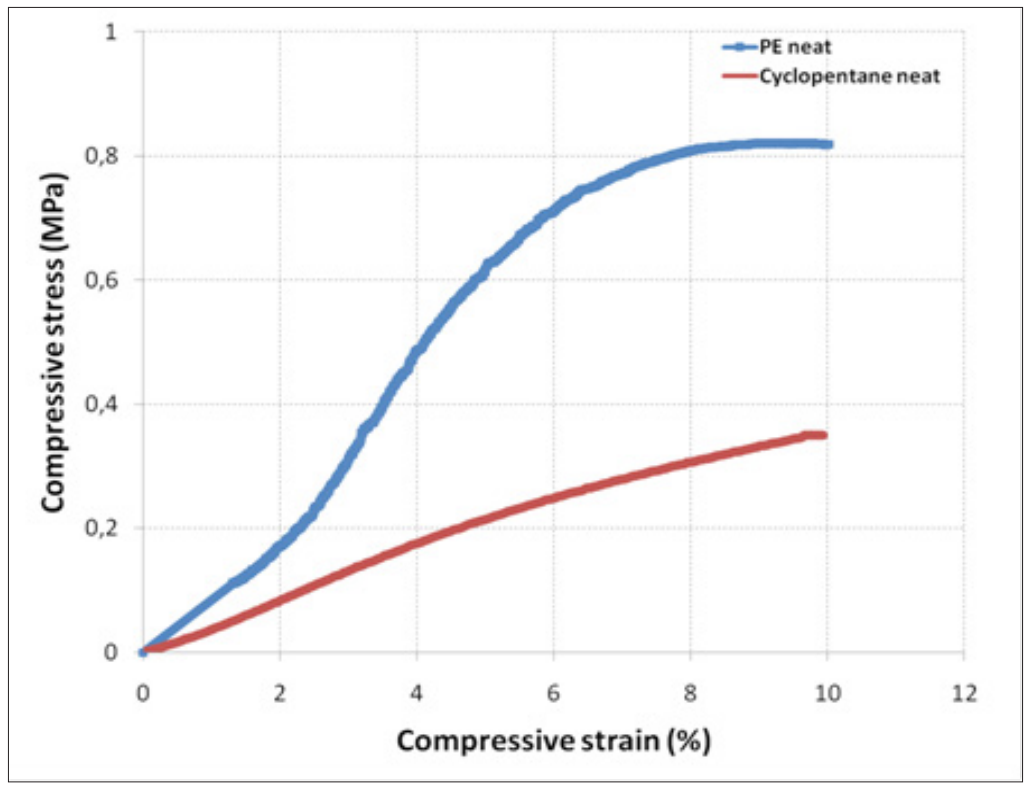

Figure 6: Compressive stress-strain curves for the pure NIPU rigid foams produced with different foaming agent.. 
Figure 6 presents typical stress-strain curves for the nanoclays modified NIPUR foams. All curves appear to follow an almost linear pattern up to $5 \%$ of compression strain. A first obvious conclusion is that reducing the density of the foam a significant decrease of the compression characteristics of the foam appears.

This pattern is completely changed when one compares the compression properties of NIPUR foams reinforced with 2 and 3\% wt of nanoclays. In the case of NIPUR foams reinforced with $3 \% \mathrm{wt}$ of nanoclays, although the density is $12 \%$ lower compared to the density concluded when $2 \%$ wt nanoclays were used, the resulted compression properties (both stiffness and strength) is 50\% higher.

The lower density is attributed to the higher number of nucleation points available during the foaming process, which is then facilitated, concluding to lower density, and at the same time the higher amount of nanoparticles, which are incorporated into the wall cells of the foam, thus reinforcing it. This effect appears at the macro-scale in the form of higher compression properties.

This behavior is not valid any more when a further increase of the content of reinforcing nanoclay particles applied. In the case of $5 \%$ wt nanoclays reinforced foams, although the density further decreases, the compressive properties of the resulted foams reduced significantly. This effect is attributed to the formation of agglomerates due to the high nanoparticles content, that are incorporated into the wall cells of the foam, but now they are behave as defects that lead the foam to early collapse. According to the recent literature [24], it is known that the compressive strength depends on the intercalated/ exfoliated and clustered content of nanoclays in the foam structure (Figure 7).

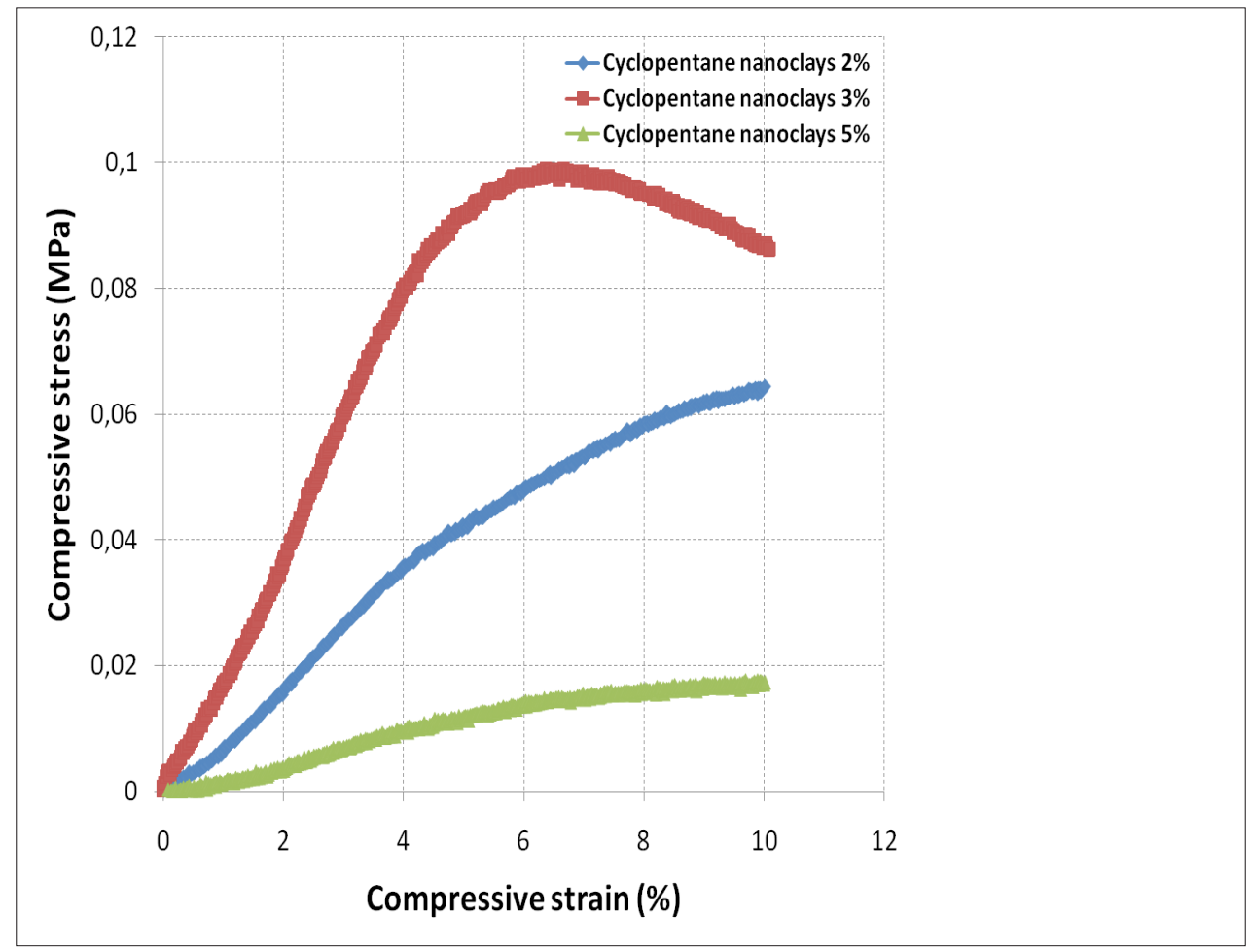

Figure 7: Compressive stress-strain curves for the nanoclays modified NIPU rigid foams produced with cyclopentane foaming agent and different \% wt content of nanoclays..

\section{Conclusion}

Non-isocyanate rigid NIPU foams were developed using a commercially available compound. Two different types of blowing agents were used, petroleum ether and cyclopentane. The latter one led to lower density foams. Based on that, nanoclays at different \% wt content were added in the case of the rigid foams, where cyclopentane used as foaming agent, to investigate their effect on the density and the compressive properties of the foam. The following are the significant features observed:

1. Petroleum ether as blowing agent leads to a heavier rigid NIPU foam compare to cyclopentane.

2. Cyclopentane as blowing agent results to thinner and more homogeneous cell size and consequently to lighter foams.
3. Nanoclays provide a mean to control the density of foams.

4. Nanoclays act as nucleating agent and lead to more uniform foam structures with smaller cells.

5. The foam with $3 \%$ wt of nanoclays exhibit the higher compressive properties, both stiffness and strength.

In the case of foam with $5 \%$ wt of nanoclays, the lower density was achieved, however the presence of significant number of agglomerates at the wall of the foam cells weaken the mechanical performance of the foam.

\section{References}

1. Randall D, Lee S (2002) The polyurethanes book. Huntsman Polyurethanes, Belgium. 
2. Narine SS, Kong X, Bouzidi L, Sporns P (2007) J Am Oil Chem Soc 84: 65.

3. Somani KP, Kansara SS, Patel NK, Rakshit AK (2003) Int J Adhes 23: 269.

4. Velayutham TS, Majid WHA, Ahmad AB, Kang GY, Gan SN (2009) Prog Org Coat 66: 367

5. Chian KS, Gan LH (1998) Development of a rigid polyurethane foam from palm oil. Journal of Applied Polymer Science 68(3): 509-515.

6. Meng, Fanzeng, Ding, Xuejia (2015) The preparation and performance study of mdi-based water-blown flexible polyurethane foam. AASCIT Journal of Materials 1.

7. Petrović, Zoran S (2008) Polyurethanes from vegetable oils. Polymer Reviews 48.

8. Pfister DP, Xia Y, Larock RC (2011) Recent advances in vegetable oilbased polyurethanes. ChemSusChem 4(6): 703-717.

9. Babb DA (2012) Polyurethanes from renewable resources. Advances in Polymer Science 245.

10. Lyon, Garret, Goldblatt L (1962) Solvent-blown, rigid urethane foams from low cost castor oil-polyol mixtures. Journal of American Oil Chemists' Society 39(1): 69-71.

11. Baser SA, Khakhar DV (1993) Castor oil-glycerol blends as polyols for rigid polyurethane foams. Cellular Polymers 12.

12. Wang HJ (2008) Biodegradable foam plastics based on castor oil. Biomacromolecules 9: 615-623.

13. Palanisamy A, Rao BS, Mehazabeen S (2011) Diethanolamides of castor oil as polyols for the development of water-blown polyurethane foam. Journals of Polymers and the Environment 19.

14. Ogunleye 00, Oyawale FA, Suru E (2007) Effects castor oil on the physical properties of polyether based flexible polyurethane foam. Global Journal of Biotechnology \& Biochemistry 2.
15. Cinelli, Patrizia, Anguillesi, Irene, Lazzeri, et al. (2013) Green synthesis of flexible polyurethane foams from liquefied lignin. European Polymer Journal 49(6): 1174-1184.

16. Bilbao R (1996) Kinetics of the thermal decomposition of polyurethane foams in nitrogen and air atmospheres. Journal of Analytical and Applied Pyrolysis 37(1): 69-82.

17. Hobbs ML, Erickson KL, Chu TY (2000) Modeling decomposition of unconfined rigid polyurethane foam. Polymer Degradation and Stability 69(1): 47-66.

18. Jiao L (2013) Thermal degradation characteristics of rigid polyurethane foam and the volatile products analysis with TG-FTIR-MS. Polymer Degradation and Stability 98(12): 2687-2696.

19. Wang Z, Pinnavaia TJ (1998) Nanolayer reinforcement of elastomeric polyurethane. Chemistry of Materials 10(12): 3769-3771.

20. Chang J, An YU (2002) Nanocomposites of polyurethane with various organoclays: Thermomechanical properties, morphology, and gas permeability. Journal of Polymer Science, Part B: Polymer Physics 40(7): 670-677.

21. Chen TK, Tien Y, Wei K (2000) Synthesis and characterization of novel segmented polyurethane/clay nanocomposites. Polymer 41(4): 13451353.

22. Cao X, Lee J, Widya T, Macosko C (2005) Polyurethane/clay nanocomposites foams: processing, structure and properties. Polymer 46(3): 775-783.

23. Mondal, Khakhar (2007) Rigid polyurethane-clay nanocomposite foams: preparation and properties. Journal of Applied Polymer Science 103(5): 2802-2809.

24. Nurfatmah N, Pauzi PN, Majid RA, Dzulkifli MH, Yahya MY (2014) Development of rigid bio-based polyurethane foam reinforced with nanoclay. Composites Part B: Engineering 67: 521-526.

For possible submissions Click below: 